\title{
Multiplicidade política entre as capturas e as resistências dos novíssimos movimentos sociais e coletivos da Grande Vitória
}

\author{
Political multiplicity among captures and resistances in the \\ newest social movements and collectives \\ in the Great Vitoria Area
}

\section{Multiplicidad política entre las capturas y las resistências de los nuevísimos movimientos sociales y colectivos del Área de Gran Vitória}

Recebido em 31-08-2020

Modificado em 21-10-2020

Aceito para publicação em 06-11-2020

doi) https://doi.org/10.47456/simbitica.v7i3.33698

\section{Paulo Edgar da Rocha Resende}

Orcid: 0000-0002-2588-2527

Pós-doutorando em ciências sociais na Pontifícia Universidade Católica de São Paulo; Doutor e Mestre em ciência política pela Universidade Autónoma de Barcelona, Espanha. E-mail: pauloedgar.rresende@gmail.com

\section{Maria Luiza Pereira Pacheco}

Orcid: 0000-0002-9233-1864

Bacharel em Relações Internacionais pela Universidade Vila Velha/ES e Mestra em Relações Internacionais Estudos da Paz, Segurança e Desenvolvimento pela Universidade de Coimbra, Portugal. E-mail: malupacheco1009@gmail.com

\section{Valéria Barros dos Santos Marchesi}

Orcid: 0000-0001-7915-371X

Mestra em Sociologia Política e Bacharel em Administração pela Universidade Vila Velha/ ES, Brasil. E-mail: leiamarchesi_br@hotmail.com

\section{Resumo}

No ativismo hodierno tem se ampliado a gama de repertórios organizativos, relacionais e de ação, se fazendo necessário observar e analisar tal diversidade com seus respectivos sentidos políticos. Para tanto, discutimos as intensidades com que distintos coletivos e movimentos da Grande Vitória, no momento da pesquisa, em meados de 2013, reproduziam ou rompiam com padrões organizativos, relacionais e dos repertórios de ação, com base nas noções de captura, dissidência, incidência e resistência. Com distintas técnicas de coleta de dados e análise baseada em proposições políticas pósestruturalistas, discutimos as inovações e as singularidades dos grupos considerando seus potenciais de provocar transformações sociais. As maiores inovações e potenciais foram localizadas naqueles que se pode denominar novíssimos movimentos sociais e coletivos, que mais se aproximam de formulações de resistência. Palavras-chave: Movimentos sociais; resistências; ativismo; pós-estruturalismo. 


\section{Introdução}

Nas últimas duas décadas temos verificado em cidades de diversos países novas ondas de ativismo, protestos, mobilizações, redes de associativismo, coletivos e movimentos sociais, que têm atraído a atenção de pesquisadores, jornalistas e lideranças político-partidárias. Na herança dos movimentos antiglobalização e no avançar da hiperconectividade global, vemos um despertar de novas culturas políticas que refletem diretamente nas formas de engajamento em lutas tanto micro quanto macropolíticas. Não trataremos aqui de buscar identificar homogeneidade nas formas de pensar e agir de multiplicidade de ativismos e ações coletivas, entretanto partimos da premissa, bastante aceita na disciplina, de que cada contexto político implica determinadas oportunidades e constrições para o engajamento (Tilly, 1978; McAdam, 1982). Isso afeta tanto a subjetividade dos ativistas, a forma de conceber os problemas políticos, suas causas e consequências, como as formas com que se organizam, atuam coletivamente e os resultados que produzem (McAdam; McCarthy; Zald, 1999).

Em sociedades de controle $^{1}$ (Deleuze, 2001), como as hodiernas, o indivíduo é chamado a participar das gestões governamentais e empresariais para que seu capital humano seja tão útil quanto possível para a produção social. O governo das condutas alcançou um estágio tão avançado que a hiperconectividade em redes sociais digitais tem possibilitado controle permanente de si e do outro, gerando um novo tipo de ativismo, o cyberativismo, com suas modulações algorítmicas (Da Silveira, 2018) ${ }^{2}$. Simultaneamente, as instituições políticas representativas que se propõem a oferecer espaço de poder político governamental a grupos majoritários e minoritários, têm sido cada vez mais desacreditadas (Graeber, 2015).

Seja devido à lógica acumulativa e centralizadora do poder estatal, que produz corrupção e cooptação de lideranças populares, seja pelos compromissos macroeconômicos com o mercado financeiro global, que limitam o poder de ação dos governantes, há em escala planetária um esvaziamento de projetos políticos transformadores que frustram cidadãos eleitores. A deslegitimação das instituições políticas, acompanhada da precarização do trabalho, das políticas de austeridade fiscal, do isolamento e da hiperconectividade digital, têm sido determinantes para a produção de novas formas de ativismo. Na busca de reinvenção

\footnotetext{
1 A noção de sociedade de controle (Deleuze, 2001) expressa um novo contexto social em que os comportamentos dos indivíduos são modulados de forma ininterrupta por meio de tecnologias de controle e monitoramento, que contam com a coparticipação e adesão de cada um.

${ }^{2}$ Conforme explica Da Silveira (2018), "A noção de modulação é mais adequada para tratar dos processos de formação de opinião nas plataformas de relacionamento online, especialmente, nas chamadas redes sociais". Isso ocorre por meio da modulação dos algoritmos que filtram e selecionam as opções e os caminhos "de interação e de acesso aos conteúdos publicados. A modulação é um processo de controle da visualização de conteúdos, sejam discursos, imagens ou sons" (Da Silveira, 2018:36-37).
} 
de relações sociais abaladas pelo novo regime de trabalho individualizado, intelectual e em empresas, emerge uma ampla diversidade de formas organizativas e táticas de ação que merecem ser observadas em detalhes.

Diversos estudos têm buscado decodificar e compreender o que esses novos ativismos apresentam de novo e de particular (Augusto, 2017; Augusto; Rosa; Resende, 2016; Castells, 2013; Day, 2005; Gohn, 2013, 2017; Graeber, 2015; Negri; Hardt, 2014; Perez; Souza, 2017; Resende e Rosa, 2017). O que diferenciariam esses movimentos hodiernos daqueles "novos movimentos sociais" - que emergiram na década de 1970 com pautas identitárias, confrontos simbólico-culturais e reivindicação de reconhecimento - e daqueles movimentos antiglobalização, que ganharam força após Seattle ${ }^{3}$ ?

Para responder à questão, destacaremos os pontos principais dos argumentos de estudiosos que identificaram e estão buscando descrever uma nova onda de ativismo, denominada por alguns 'novíssimos movimentos sociais' (Augusto, 2017; Augusto; Rosa; Resende, 2016; Day, 2005; Gohn, 2013, 2017; Perez; Souza, 2017). Em seguida, apresentaremos e discutiremos alguns elementos marcantes do ponto de vista da inovação política de grupos organizados com objetivos políticos não institucionais na região metropolitana de Vitória, no Estado do Espírito Santo. Por último, analisaremos as multiplicidades de estratégias e alinhamentos políticos realizados pelo ativismo hodierno pelo paradigma da captura e da resistência.

O método de análise adotado, inspirado na cartografia de Deleuze e Guattari ${ }^{4}$ e nas categorias de captura e resistência de Michel Foucault (Branco, 2001; Foucault, 2009), se baseia na observação das intensidades, limites e bifurcações, ou seja, as potências que os ativismos apresentam para a transformação social, assim como suas singularidades, suas ambiguidades e, principalmente, as intensidades com que inovam em seus repertórios de ação e formas organizativas. Nossa atenção está posta às possibilidades de desterritorialização e reterritorialização (Deleuze; Guattari, 1996), ou seja, nos deslocamentos de referenciais anteriormente adotados e no estabelecimento de novos referenciais, sejam eles no campo

\footnotetext{
${ }^{3}$ Em novembro de 1999, na cidade de Seattle, manifestantes de distintas agendas e posicionamentos políticos, através do emprego de táticas de ação direta, impediram a realização de reunião de cúpula ministerial da Organização Mundial do Comércio.

${ }^{4}$ Entendemos o método cartográfico de Deleuze e Guattari como a exploração do objeto de estudo com atenção especial aos seus movimentos, seus fluxos, às formas como tem se realizado e se visibilizado na ótica dos observadores, no momento da observação. Trata-se de uma análise que busca fugir de apriorismos dos julgamentos transcendentes que avaliam o objeto com base no que se supõe ou se espera que ele seja, circunscrito a essências estáticas. Ao se abrir para a flutuação ontológica da imanência do objeto, o pesquisador ativa processos de devir, no qual ele próprio se permite afetar e ser afetado pela vivência no campo de pesquisa (Cf.: Deleuze; Guattari, 1996; Rolnik, 1989).
} 
cognitivo, da performatividade identitária ou das ações. O valor epistemológico de tal procedimento de pesquisa se afirma na necessidade de compreensão do associativismo no momento histórico em que este se diversifica. Dessa forma, as abordagens tradicionais perdem a capacidade de encontrar sentido em grupos que porventura fogem à regra do que seria um movimento social segundo a literatura científica.

$\mathrm{O}$ artigo apresenta e discute resultados da coleta de dados de pesquisa exploratória realizada através de entrevistas semiestruturadas, grupos focais e observações etnográficas, consulta a materiais próprios de cada grupo e de mídias alternativas. Foram analisados grupos de ativistas constituídos em estruturas mais formalizadas e outras menos, mas sempre ostentando atuações políticas reivindicativas e/ou de ação direta, na Grande Vitória, no Espírito Santo, sem a pretensão de abarcar a todos os movimentos e grupos existentes na região.

\section{Capturas e resistências}

É produtivo para a análise sociopolítica observar o que ocorre entre as dinâmicas de capturas, ou seja, de continuidades e repetições, de um lado, e as dinâmicas de resistências, rupturas e subversões, de outro. As duas categorias podem ser entendidas como tipos ideais entre as quais podemos encontrar um contínuo de multiplicidade de práticas, que se aproximam mais da captura ou da resistência e que por vezes se entrelaçam, se misturam e se confundem, perturbando a nitidez da percepção. Por esse motivo não são polos dicotômicos, pois na resistência pode haver dimensões, práticas, discursos, racionalidades capturadas, assim como na captura podem ser localizadas microrrelações, ações, pensamentos autônomos ou de confronto, que resistem a uma captura completa.

O desafio da análise cartográfica é justamente possibilitar a percepção das nuances, das partículas menores que fazem qualquer fenômeno ou corpo fugir de essências estáticas, monolíticas, embora estas sejam mais facilmente identificáveis pela sociologia acadêmica. A partir dessa ótica, buscamos verificar como grupos associativos diversos, com distintos projetos políticos ou compromissos sociais, têm se organizado internamente, se relacionado com instituições políticas e estruturado suas ações coletivas. Consideramos produtivo avaliar a potência política desses grupos, embora cientes dos limites metodológicos de não os haver acompanhado ao longo de um período maior de tempo. Tal estratégia teria sido mais proveitosa para apreender as particularidades dos movimentos, os fluxos de variações que fazem com que um grupo não seja visto como preso a uma essência estática. O que 
produzimos, portanto, é uma aproximação com vistas a compreender, ainda que parcialmente, suas complexidades.

A perspectiva da captura, que se verifica em assujeitamentos, assimilações e repetições de estruturas de pensamento e ações dominantes, como forma de constituição da ação política, pode ser melhor compreendida se a subdividirmos em dois módulos de distintas intensidades: o da incidência e o da dissidência, que adaptamos de Subirats (2005). A incidência pode ser operacionalizada na participação direta e indireta nas instituições políticas e processos decisórios governamentais. Estar dentro das instituições, "implica de fato reforçar essas instituições, legitimar sua maneira de fazer e de atuar" (Subirats, 2005:16). Na prática, se constitui como a forma mais capturada e efetiva de participar da formulação de políticas públicas, gerenciando e controlando populações e recursos através do aparato estatal. Nas sociedades de controle, os indivíduos são chamados a compartilhar seus conhecimentos com o Estado e organizações sociais e econômicas, a fim de serem reconhecidos, identificados e, principalmente, úteis ao funcionamento e aprimoramento de tais organizações (Cf. Deleuze, 2001; Passetti, 2007; Tótora, 2006).

A noção de dissidência parte do entendimento de que "outra política é possível" (Subirats, 2005:16) e que "nem toda luta levantada pelos grupos sociais é, efetivamente, luta de resistência ao poder" (Branco, 2001:241). O conceito é útil para a compreensão da particularidade de movimentos que performatizam combates e confrontos, mas reproduzem centralizações políticas e admitem determinadas oportunidades de alianças e participações nas instituições. Nesse âmbito, se travariam "lutas de direito e pelo direito [que] acabam por instituir um campo de luta morno e demasiado convencional" (Branco, 2001:245). Ao comentar as críticas de Foucault sobre a relação dos grupos com o poder, Branco elenca três considerações. A primeira e talvez a mais importante seria que:

[...] muitas lutas supostamente contestadoras seriam, desde seu início, lutas visando à inclusão e/ou legitimação na ordem estabelecida: seria o caso das lutas pelo direito à habitação, saúde, higiene etc., que acabam consolidando as estruturas do poder e auxiliando no desenvolvimento de suas técnicas de individuação (ibid:241).

A segunda consideração seria "que toda luta acaba sendo assimilada, ao fim e ao cabo, pelas malhas do poder" (idem). Essa consideração coincide com as críticas de Day (2005), que veremos mais abaixo, que o autor denomina "hegemonia da hegemonia", ou seja, da predominância entre os movimentos sociais de lutas que buscam construir nova hegemonia a partir de seus valores e agendas políticas. A terceira consideração seria mais precisamente 
uma consequência das duas primeiras: a descrença por parte de Foucault no "potencial transformador e revolucionário dos partidos e grupos políticos” (Branco, 2001:241).

Já a resistência pode ser entendida como atitudes e lutas que não se deixam sucumbir a dinâmicas de dominação e não abdicam da autonomia política. São ativistas que "estão fora, e praticam a rebeldia diante das instituições" (Subirats, 2005:16). Como efeito, são contrários a participar ou estabelecer alianças com instituições em que há centralização do exercício de poder. Evitam proferir demandas a órgãos governamentais, criando e inventando novas possibilidades políticas e econômicas, novas vivências, novos espaços e formas de romper com instituições e valores tradicionais. Seu âmbito de ação não está amparado ou limitado por leis, regras morais ou autoridades vigentes. Como o poder que incide no indivíduo de forma a limitar sua autonomia e singularidade vai muito além das relações sociais que perpassam o Estado, as formas de resistência também vão além da luta contra as políticas e autoridades do Estado. Entendemos, a partir de Foucault, que há três tipos de lutas de resistência:

[...] contra as formas de dominação (étnica, social e religiosa); contra as formas de exploração que separam os indivíduos daquilo que eles produzem; ou contra aquilo que liga o indivíduo a si mesmo e o submete, deste modo, aos outros (lutas contra a sujeição, contra as formas de subjetivação e submissão) (Foucault, 2009:235).

Sobre o contexto em que se aplicam esses três tipos de resistência, o autor afirma que "são lutas 'transversais; isto é, não são limitadas a um país (...) não estão confinadas a uma forma política e econômica particular de governo". Não é a qualquer relação de poder que a resistência confronta, mas àquela em que o poder, a partir de privilégios sobre o saber, exerce seus efeitos "sobre os corpos das pessoas, sua saúde, sua vida e morte", produzindo violências econômicas e ideológicas, ignorando as individualidades, determinando identidades e atropelando o "direito de ser diferente". Neste sentido, "são batalhas contra o 'governo da individualização", que fragmenta a vida comunitária e contamina as relações entre as pessoas, subjugando, assujeitando e produzindo relações de dominação. "Em suma, o principal objetivo destas lutas é atacar, não tanto 'tal ou tal' instituição de poder ou grupo ou elite ou classe, mas, antes, uma técnica, uma forma de poder (...) que faz dos indivíduos sujeitos" (Ibid.:234-235). Por último, é importante destacar o nível tático e radical que o autor atribui à resistência e que nos possibilita localizá-la naquele ativismo individual e coletivo, não somente hodierno, que não se molda por utopias, mas por urgências do seu momento presente: 
São lutas 'imediatas' por duas razões. Em tais lutas, criticam-se as instâncias de poder que lhes são mais próximas, aquelas que exercem sua ação sobre os indivíduos. Elas não objetivam o 'inimigo mor', mas o inimigo imediato. Nem esperam encontrar uma solução para seus problemas no futuro (isto é, liberações, revoluções, fim da luta de classe) (...) São lutas anárquicas (Ibid.:234).

Como visto, temos nas categorias de captura, incidência, dissidência e resistência uma ferramenta de análise que, longe de servir como régua medidora de polaridades, nos fornece referências para analisar as potências políticas de ampla miríade de formas de ativismo e lutas sociais. Cientes das possibilidades de continuidades e rupturas, a seguir verificamos na literatura específica as discussões sobre as novidades do ativismo hodierno.

\section{O que há de novo nos novíssimos movimentos sociais?}

Antes mesmo da emergência dos chamados "novos movimentos sociais" que marcaram as décadas de 1960 e 1970 (Cf. Melucci, 1994; McAdam, 1994), já havia em diversos países, incluindo o Brasil, grupos de ativismos que se engajavam em lutas culturais buscando reconstituir significados e relações sociais, de modo a possibilitar direitos e liberdades de minorias sociais, étnicas e culturais. Se hoje, com as facilidades conectivas possibilitadas pelos meios de comunicação digital, verificamos um fortalecimento dessas lutas, quais traços novos poderíamos identificar no ativismo hodierno? Certamente a visibilidade das lutas das denominadas minorias identitárias e sua presença na vida cotidiana das grandes cidades é apenas um desses traços.

Com vistas a contribuir com o debate, buscamos identificar alguns marcos definidores em textos ad hoc recentes que utilizam o termo "novíssimos movimentos sociais" (Day, 2005; Gohn, 2017; Augusto, 2017; Augusto; Rosa; Resende, 2016; Perez; Souza, 2017), e em outros que, ainda que não adotem tal terminologia (Castells, 2013; Negri; Hardt, 2014), reconhecem tratar-se de fenômeno novo no campo das ações coletivas, com a presença de importantes influências anarquistas.

O primeiro acadêmico a adotar o termo "novíssimos movimentos sociais" (newest social movements), Richard Day (2004; 2005), o fez a partir da percepção de que o conceito "antiglobalização" não era suficiente para cobrir "todo o espectro de resistências à nova ordem mundial" (Day, 2005:4), que surgia no "final dos anos 1990 e início dos anos 2000, cujas raízes retomam aos novos movimentos sociais dos anos 1960 (...), assim como às mais antigas tradições do socialismo marxista e anarquista" (idem). Os novíssimos movimentos seriam aqueles grupos autônomos, assim como estratégias e táticas de ativismo radical 
contemporâneo, que operam desafiando a lógica da hegemonia. São ativistas radicais por "tentarem conscientemente alterar, impedir, destruir ou construir alternativas às estruturas, processos, práticas e identidades dominantes" (idem). Lutam contra as hegemonias sem adotar o viés gramsciano da "contra hegemonia" (Cf. Laclau; Moufee, 2015), pois buscam mudanças radicais por vias alternativas à tomada do poder do Estado ou da influência sobre suas instituições. O autor se refere às "lutas que buscam provocar mudanças nas raízes, que almejam combater não somente os conteúdos dos modos atuais de dominação e exploração, mas também as formas sobre as quais se produzem” (Day, 2005:4). Para além das táticas e estratégias, sua definição de movimentos sociais, desprendida das definições tradicionais da sociologia, se ajustaria àqueles grupos que se pautam na afinidade pela afinidade, ou seja, que estabelecem "laços não universalizantes, não hierárquicos, não coercitivos, baseados na ajuda mútua e no compromisso ético comum" (ibid.:9).

Ação direta, "horizontalidade, autogestão, ausência de lideranças ou de intelectuais orgânicos, autonomia, transversalidade temática, foco na ampliação de liberdades e ampla utilização das redes sociais digitais, são algumas das novidades mais evidentes" (Augusto; Rosa; Resende, 2016:26) que verificamos nesses novíssimos ativismos. Parece cedo afirmar que essa nova onda de ativismo estaria provocando transformações significativas nas estruturas de poder, mas certamente são inovações importantes para a organização, as táticas e os significados das atuais lutas políticas.

Negri e Hardt (2014) dizem ver "muito pouco dos tradicionais movimentos socialistas nesse ciclo de lutas" (Negri; Hardt, 2014:15), em que identificam três características principais: a primeira é que "estão profundamente enraizados nas questões sociais locais e nacionais" (ibid.:14); a segunda é que "os movimentos desenvolveram mecanismos horizontais de organização" (idem), ao mesmo tempo em que rejeitaram a representação:

No Cairo, em Madri, em Atenas e em Nova York (...) não construíram quartéisgenerais nem formaram comitês centrais, mas se espalharam como enxames, e, o mais importante, criaram práticas democráticas de tomada de decisão, para que todos os participantes pudessem liderar juntos (idem).

A terceira característica seria o que denominaram "lutas pelo comum", que "contestam a regra da propriedade, igualmente se opõem à regra da propriedade pública e ao controle do Estado" (ibid.:15). Por fim, afirmam que "esses movimentos também dão novos significados para a liberdade, para nossa relação com o comum e para diversos arranjos políticos fundamentais, que excedem em alto grau os limites das atuais constituições republicanas" 
(ibid:: 16). Diante da questão de por que os ativistas do Occupy Wall Street não têm lideranças ou propostas políticas concretas, o antropólogo e ativista David Graeber é enfático:

\begin{abstract}
Foi apenas quando apareceu um movimento que se negou terminantemente a tomar o caminho tradicional, rejeitou por completo a ordem política por considerá-la inerentemente corrupta e demandou a total reinvenção da democracia americana, que as ocupações começaram a brotar por todo o país. Está muito claro que o movimento não deu certo 'apesar' do elemento anarquista. Ele deu certo 'por causa' dele (Graeber, 2015:101).
\end{abstract}

Castells (2013) aponta que apesar da conectividade dos ativistas em redes digitais ser o aspecto a receber maior ênfase em seu estudo, também há caracterização anarquista ao apresentar os movimentos que ocorreram na Espanha, Grécia, Portugal, Itália, Grã-Bretanha, Israel, EUA, Brasil, depois das insurreições árabes iniciadas em 2010: “em todos os casos, os movimentos ignoraram partidos políticos, desconfiaram da mídia, não reconheceram nenhuma liderança e rejeitaram toda organização formal, sustentando-se na internet e em assembleias locais para o debate coletivo e a tomada de decisões" (Castells, 2013:9). Para Gohn (2013),

As diferenças passam pelos campos temáticos tratados, pelos repertórios, formas de comunicação, identidades criadas, pertencimentos de classe e sociocultural, as formas como aproveitam as oportunidades políticas e socioculturais que surgem e a forma como veem os partidos e organizações políticas (Gohn, 2013:12).

Hoje, possivelmente devido à interconexão digital, que oferece excelente oportunidade estrutural para o ativismo de confrontos culturais ${ }^{5}$, as pautas identitárias têm ganhado força na mobilização individual e coletiva. De fato, pelo menos desde o surgimento dos movimentos de justiça global e das redes transnacionais de ativismo, temos observado crescente uso dos meios digitais por um ativismo que muitas vezes prescinde da vinculação a grupos formalmente organizados (Della Porta; Tarrow, 2005; Tarrow, 2005). A militância identitária, por suas características evidentes de lutas na vida cotidiana, tem ganhado enorme visibilidade com as redes sociais e, a partir dos algoritmos, se polarizado em guerras culturais de forma que, apesar da literatura sobre os novíssimos movimentos descreverem, como visto, certas características de resistência anárquica e de afinidade não hegemônica, verificamos também no Brasil pós-Junho de 2013 um forte ativismo de direita, capturado a valores neoliberais, patriarcais e conservadores (Rosa et al, 2018).

O desafio, portanto, na observação das mais novas formas de ativismo, é não prendermos o olhar somente àqueles grupos de viés marxista ou anarquista, ou àqueles que

\footnotetext{
${ }^{5}$ Onde as lutas sociais buscam influenciar ou transformar símbolos cognitivos que estruturam as relações entre indivíduos e grupos, como as lutas antifascistas, feministas, antirracistas, ecologistas e etc..
} 
adotam formas organizativas ou repertórios de ação já amplamente documentados pela literatura de movimentos sociais. Aparentemente estamos vivenciando um novo ciclo de ativismo, que se diferencia daqueles do século XX e também do início do século XXI.

Na busca por tal atualização, Gohn (2017) chama de "novíssimos" os movimentos da atualidade “criados ou 'firmados' na cena pública na década de 2010, a exemplo do Movimento Passe Livre (MPL) e do Movimento dos Secundaristas, de um lado; e, de outro, o Vem Pra Rua (VPR) e o Movimento Brasil Livre (MBL), criados em 2014" (Gohn, 2017:9). Ele considera que na multiplicidade de referências os jovens têm preferido se organizar em coletivos, mais que em movimentos, pois os primeiros teriam "agrupamentos fluidos, fragmentados, horizontais, e muitos têm a autonomia e a horizontalidade como valores e princípios básicos. Coletivos autodenominam-se como ativistas, e não militantes de causas, vivem experiências e experimentações." (Gohn, 2017:23). Ou seja, caímos mais uma vez nas aproximações com o anarquismo, "há grande influência de ideários anarquistas e libertários" (idem), que explica o que há de mais inovador no ativismo hodierno de resistência, mas não é suficiente para compreender o ativismo de captura que encontramos no VPR, no MBL ou nos youtubers de extrema direita.

É com base nessa carência de precisão teórico-metodológica que realizamos esta pesquisa de base exploratória a fim de identificar as novidades de uma gama diversa de ativismos. Para avaliar as consistências de tais novidades e verificar se não se trata apenas de oportunidades conjunturais, buscaremos avaliá-las a partir das categorias de potência política em termos de resistências e capturas. Consideraremos também as repercussões que as novas mídias digitais provocam em suas formas de organização, ação e resultados.

\section{Cartografando os movimentos da Grande Vitória, ES}

O propósito desta exploração empírica é conhecer, compreender e dar sentido às singularidades do ativismo no Espírito Santo, em particular do que atua na região metropolitana de Vitória. Ao pesquisar a grande variedade de formas de organização e atuação coletiva foi possível aproximar a análise aos aspectos de interesse da pesquisa - as multiplicidades de novas formas de ação política não institucional - identificando as 
singularidades e os aspectos em que os grupos mais combativos se diferenciam daqueles mais capturados à governamentalidade ${ }^{6}$ predominante.

Para este artigo, movimentos sociais e coletivos foram analisados em três dimensões, organização interna, repertórios de ação e relações externas com outros grupos e instituições. Entendemos que movimentos e coletivos são grupos sociais que encampam processos políticos, mas se distinguem principalmente pelo grau de formalização. A título de comparação e caracterização, destacamos os grupos pesquisados que melhor pudemos levantar dados. Como se trata de uma aproximação, não tivemos pretensão, em nenhum dos casos, de apresentar um detalhado retrato dos mesmos. Para fins didáticos, apresentamos as características principais dos grupos separados em categorias descritivas.

\section{Capturas e resistências na forma organizativa}

Alguns grupos associativos têm apresentado estrutura organizativa mais rígida e formalizada, se aproximando em grande medida da institucionalização produzida e estimulada pelo Estado, se constituindo, por exemplo, como ONGs (Organizações Não Governamentais) ou OSCIPs (Organização da Sociedade Civil de Interesse Público). Esse tipo de formalização institucional, de incidência, apresenta a estrutura organizativa mais eficaz para interagir com o Estado, através de, por exemplo, financiamento público, benefícios fiscais, participação em conselhos consultivos, acesso a gabinetes para reivindicação de demandas, entre outros benefícios.

Grupos políticos nesses formatos mais tradicionais, ainda que abriguem ativistas envolvidos com outros coletivos, ou que apoiem outros coletivos, não parecem ostentar combatividade e confronto com instituições e lideranças políticas. É o caso da Associações de Moradores da Praia da Costa, da ONG ambientalista Sociedade Sinhá Laurinha e do Diretório Central de Estudantes (DCE) da Universidade Federal do Espírito Santo. No momento desta pesquisa, não apresentavam formatos novos de organização e de repertórios de ação. Funcionando através de organização burocrática, chegavam a possuir divisão de cargos como diretoria, secretaria, tesouraria, eleições regulares, procedimentos formais de participação e votação em reuniões. Para completar, encontramos em comum entre os grupos o uso de canais de diálogo já estabelecidos com instituições políticas representativas, como

\footnotetext{
${ }^{6}$ Foucault localiza a governamentalidade no assujeitamento do indivíduo a preceitos morais, comportamentais, políticos e econômicos de interesse do governo do Estado na gestão de uma determinada população (Foucault, 2006).
} 
partidos, prefeituras, mandatos de vereadores e/ou deputados, que facilitam a incidência nessas esferas políticas e a obtenção de recursos ou decisões que atendam a suas agendas.

As sociedades atuais - denominadas "sociedades de controle", por Deleuze (2001) -, altamente controladas por redes digitais e algoritmos, apresentam constante demanda por formação de capital humano e pelo aproveitamento desse capital no aprimoramento de decisões coletivas. Adequadas à racionalidade neoliberal, a separação entre Estado e sociedade não se evidenciaria, pois, a integração entre ambos se materializa na profusão de instituições sociais, associações filantrópicas, ONGs, conselhos, movimentos e coletivos, que acabam se constituindo como extensão do Estado (Cf. Passetti, 2007; Tótora, 2006). Na medida em que o paradigma neoliberal força governos a desmontarem suas estruturas burocráticas de serviços públicos e de atenção à população, ou que a política representativa fechada nos gabinetes necessita de um braço de contato com a população para melhor servi-la, esses grupos se fortalecem e são parcialmente absorvidos pela estrutura estatal. Pela teoria da mobilização de recursos (McCarthy; Zald, 1987), poderíamos sugerir que esses grupos formalizados estão adotando um formato de movimento social eficaz para a mobilização de apoio popular, assim como para a obtenção de bons rendimentos políticos e econômicos.

Para o propósito deste trabalho, de observar as diferenças entre distintos coletivos e movimentos sociais, é produtivo contrastar modelos organizativos mais formais constituídos, e institucionalizados de outros mais informais. O coletivo autodenominado Anonymous - ES é um bom exemplo. No momento da coleta de dados para este trabalho, em 2013, o grupo aparentava distanciamento de comprometimento ou vinculação com quaisquer instituições, embora estivessem atentos aos acontecimentos sociais e políticos locais e nacionais.

Sem uma hierarquia interna definida e formalizada, o Anonymous - ES tendia a permitir a participação mais livre dos associados, apesar de que a entrada no coletivo requeria algum grau de confiança, devido provavelmente a suas atividades que extrapolam legalidades. Em suas atuações, ativistas ligados ao coletivo afirmaram haverem exposto dados sigilosos de instituições estatais revelando remunerações abusivas e possíveis fraudes. Ao evadir controles cibernéticos e expor dados que deveriam ser públicos, o grupo transita entre a dissidência e a resistência.

Em um grupo focal realizado em um parque de Vitória, com cinco jovens que permaneceram todo o tempo com os rostos cobertos por máscaras, foi destacada a necessidade de implantação de uma "hiperdemocracia" no Brasil, em que o povo como um todo seria o responsável pela tomada de decisões, sem mediações. Segundo afirmaram, o Anonymous - ES "não segue uma linha comunista, capitalista ou anarquista; nem esquerda, nem direita". 
Entretanto, na nossa compreensão tal projeto político que se assemelha a uma democracia direta os aproximaria da noção de dissidência. Conceituado pelos entrevistados como “ideologia" e não "movimento social”, o coletivo buscaria a conscientização da população por intermédio da disseminação de informações, principalmente pela internet. Com organização difusa, em rede horizontal, suas decisões são coletivas, discutidas, consensuadas e, segundo eles, implementadas por todos.

Nas dinâmicas internas, o Movimento Bicicletada, que durante a coleta de dados buscava promover a substituição de veículos automotores por bicicletas na mobilidade urbana, tendia a considerar a opinião de seus diversos participantes. A atuação em atos temporários e com objetivo determinado levavam o movimento a se definir quase como evento de encontros periódicos de incentivo ao uso da bicicleta. Não há líderes, suas decisões são tomadas por consenso e, segundo os entrevistados, ao menos durante a realização da pesquisa, não possuíam como objetivo fazer reivindicações ao Estado. A preocupação principal declarada é a recuperação do meio-ambiente e a promoção de vidas saudáveis. Sendo assim, o viés de resistência fica evidente ao buscarem, através da micropolítica da vida cotidiana, instituir formas de locomoção alternativa à predominante no mercado, no Estado e na organização do espaço urbano.

Organizações horizontais com relações de poder fluidas, com tarefas e capacidades decisórias bem distribuídas, também se aproximam da noção de resistência, pois revelam rejeição à forma hierárquica e burocrática moderna que tão bem tem servido às instituições que reproduzem relações de dominação, como a igreja, o Estado ou as corporações com fins lucrativos. Como visto, organizações mais formalizadas que seguem em maior grau a estrutura estatal tendem a encontrar mais oportunidades políticas nas instituições do Estado. Embora a proximidade com o governo facilite que os representantes ouçam as demandas do povo, os coletivos e movimentos que agem de maneira independente conseguem promover seus eventos sem entraves burocráticos. Como exemplo disso, temos que o Movimento Bicicletada buscava conscientizar a sociedade dos benefícios do uso da bicicleta, promovendo suas ações por meio de convites menos formais, usando redes sociais e vias públicas.

Como visto, na relação mantida com instituições estatais verificamos uma certa coerência entre as formas adotadas de organização interna e as relações que os grupos estabelecem com órgãos governamentais. Grupos ostentando maior grau de hierarquização interna tendem a ter mais proximidade com pautas governamentais e contatos privilegiados com representantes e lideranças políticas. Sendo assim, os coletivos e movimentos que não 
demonstraram compromisso com esse modo de organização não possuíam tanta interlocução com representantes políticos ou resultados tão satisfatórios em políticas estatais.

Grupos muito estáveis e organizados da sociedade civil tendem a ser esvaziados do caráter conflitivo e assumem para si a governamentalidade do Estado, atendendo em alguma medida aos interesses deste. Burocracia na forma de organização, com tomada de decisões centralizada, representações de interesses, canal estável com órgãos estatais receptores de demandas, etc. são características marcantes da incidência. A estabilidade que demonstram e o pragmatismo de suas decisões, pelo contrário, configuram tais grupos como órgãos adjacentes ao Estado. Trata-se de um exemplo de sociedade organizada sem fins econômicos, porém capturada pela política convencional das instituições estatais.

Não é difícil compreender a natureza capturada da racionalidade burocratizada, que é estruturada com base na hierarquia e na dominação, que constituem o próprio esqueleto de sustentação do Estado. Ao estudar as proximidades no anarquismo de Max Stirner e Gilles Deleuze, Newman (2005) destaca que ambos entendem que o Estado é uma abstração que vai para muito além das instituições. Ele habita nas condutas, nas formas de se relacionar e de se organizar dos sujeitos que adotam determinadas racionalidades que reproduzem essências, dogmas e hierarquias, pois sem essas reproduções, não haveria estruturas institucionais tão poderosas como as que formam o Estado (Newman, 2005). Na modernidade, a noção do indivíduo sedentário (Deleuze; Guattari, 1996; Schopke, 2012) é verificável naquele que reproduz a ordem, ao invés de rompê-la em milhares de formas possíveis.

\section{Resistência na organização, incidência na articulação}

O Movimento Nacional de População de Rua (MNPR) da Grande Vitória, no momento de nossa pesquisa, promovia ações coletivas organizadas que objetivavam alcançar mudanças sociais para a população de rua por meio da atuação política. O grupo era formado por uma coordenação de pessoas que já estiveram em situação de rua. Trabalhavam de forma horizontalizada, procurando a harmonia de decisões, mas buscando também constituir uma ponte entre a rua e os órgãos governamentais competentes. Existia uma coordenação nacional, e cada estado tem representantes que usam da mesma linguagem para se comunicar. A reunião semanal entre seus membros era o meio de debater a situação local e criar mecanismos estratégicos de inserção da ideia do movimento tanto na sociedade como no Governo. 
Desta forma, observa-se que as decisões eram formadas no coletivo, juntamente com grupos de apoio voluntários, como Igrejas, academias, grupos de advogados, entre outros. O movimento procurava ter visibilidade no cenário social e político participando de eventos, seminários e congressos a nível nacional, como por exemplo de direitos humanos e de habitação. Para aprimorar a visibilidade do grupo, seus ativistas levavam pautas de interesse da população de rua para outros movimentos. Exemplo disso seria a participação do grupo em eventos relacionados à mulher, em que levavam a problemática da mulher de rua, assim como em movimentos negros, homossexuais e de portadores de deficiências, conforme nos foi relatado por um participante. O grupo também participava de audiências públicas e utilizava os mais variados espaços participativos para sua inserção, como Fóruns de mulheres, de negros, da juventude, Conselho de Direitos Humanos, redes sociais, blogs, igrejas e pastorais sociais.

Com o tempo, o MNPR de Vitória adquiriu mais espaço para diálogo com o Governo, mas ainda assim entendia-se que a mobilização social teria um papel relevante no sentido de conscientizar e sensibilizar a sociedade sobre a situação real, distinta da veiculada pelos grandes meios de comunicação. O movimento sofre com o Estado omisso que não assume a falta de moradia como um problema social relevante. As políticas estatais deveriam, segundo os ativistas, trabalhar a questão indo além das drogas e da criminalidade, levando em consideração o indivíduo. Segundo avaliação dos entrevistados, na Grande Vitória o movimento ainda encontrava resultados aquém aos de movimentos equivalentes em São Paulo e Minas Gerais.

Estrategicamente, o contato mais próximo com instituições e líderes governamentais facilitaria o sucesso político institucional de suas pautas sob reivindicação, ainda que os obrigasse a suavizar críticas ou a abandonar a radicalidade de propostas. Essa proximidade de contato muitas vezes implicaria na participação de militantes de movimentos em partidos políticos, em órgãos estruturados pelo Estado - tais como instituições participativas, conselhos gestores e audiências públicas - na admissão de intermediários para estabelecer contatos com políticos ou até mesmo na posse em cargos públicos (Cf. Abers; Von Bülow, 2011; Lavalle; Von Bülow, 2014). Sobre essa relação entre as formas de ação coletiva e a interação com o Estado, Carlos (2011), pondera que os movimentos sociais não são puros, são complexos, heterogêneos e não necessariamente apresentam coerência e estabilidade. Devem ser considerados em suas dimensões não só organizativa, mas também relacional e cultural. Atentos a essas considerações, buscamos justamente não limitar nossas observações a somente uma dessas dimensões e a observar a interpenetração entre movimentos e 
instituições. Por outro lado, é certo que o aprofundamento da interação entre movimentos e instituições corrói a fronteira rígida entre sociedade e Estado.

\section{Resistência organizativa e pautas dissidentes}

O Coletivo Feminina, como o próprio nome sugere, era designado como um coletivo por ter parte de ideias individuais que juntas formam um ideal comum a ser defendido que tem como foco a questão da mulher. Não existia, no momento das entrevistas, uma estrutura de cargos dentro do grupo, e sim responsabilidades designadas a cada uma de acordo com afinidades ou facilidades, o que representa no fim uma horizontalidade de decisões. Na tomada de decisões e estratégias de ação todas as envolvidas podiam participar, de acordo com o que nos foi relatado. Os temas discutidos tinham como base questões relacionadas a gênero, patriarcado, machismo e direitos da mulher. Procuravam visibilizar seus posicionamentos através de ações independentes como trabalhos em penitenciarias, promoção de festivais, encontros, festas, seminários temáticos, redes sociais e a Marcha das Vadias.

O grupo procurava discutir a questão da mulher em suas diversas intersecções sociais, como camponesas, periféricas, indígenas, negras, homossexuais etc. Até o momento das entrevistas, o coletivo não havia adotado como objetivo incidir em políticas públicas governamentais, prezando mais pela conscientização, práticas cotidianas e a autonomia. Houve participação em editais e a realização do seminário da Marcha das Vadias, porém, segundo os relatos não teria havido um trabalho de interlocução direta com o Governo. Ainda que suas pautas requeriam respostas de políticas públicas direcionadas, seus repertórios de ação se mantiveram, no momento da entrevista, na resistência expressada pela autonomia em relação ao Estado.

O coletivo utilizava como meio de visibilidade as redes sociais, principalmente para a mobilização e organização de atos de protesto. Para o grupo, a falta de comunicação do Governo com os movimentos sociais era um dos principais problemas, pois as políticas públicas não chegariam ao seu destino de forma apropriada, o que seria um reflexo do claro desinteresse do Governo para com as minorias. Segundo as ativistas do grupo, os movimentos sociais são a principal ponte que leva a voz dos oprimidos da sociedade ao Estado, por isso a democracia ideal seria aquela em que estes movimentos em ascensão comandariam o Governo, exercendo poder além do legislativo e do executivo.

O Movimento Não é por 20 centavos nasceu no Espírito Santo por influência de outros movimentos de mesmo nome em vários outros estados do país, durante os protestos de junho 
de 2013. Sua organização interna perene somente podia ser verificada em suas assembleias. Qualquer ativista presente tinha direito de participar e de expressar sua opinião sobre a pauta e sobre as reivindicações do movimento, conforme relatado. O grupo se caracterizava por uma plataforma reivindicativa temporária, em que se aglutinavam diversos grupos e movimentos por meio de uma pauta específica do momento. As ações do grupo eram principalmente passeatas e manifestações para chamar a atenção da sociedade e do governo para a pauta definida em suas assembleias. Além do congelamento no aumento das tarifas de ônibus em Vitória, a descontinuidade da cobrança de pedágio na ponte que liga a capital com a cidade de Vila Velha, o grupo também reivindicava a desmilitarização da polícia militar.

A Marcha da Maconha se constituía anualmente em um conjunto de atividades a favor da descriminalização das drogas, replicando os atos em várias cidades do país. Adotava como estratégia, em 2014, a visibilização dos custos sociais da proibição, como a corrupção, o encarceramento em massa e a violência do tráfico. Seus ativistas consideravam a informação a principal "arma" utilizada para romper tabus e pré-conceitos e as redes sociais auxiliavam em grande parte a articulação e difusão. A cada ano a Marcha demonstrava mais força de expressão e repercussão, angariando novos adeptos, principalmente entre os jovens. Ainda que buscasse afetar a formulação de leis e políticas públicas governamentais, o movimento não utilizava canais institucionais de diálogo. Na organização do movimento na Grande Vitória não existia representante ou liderança identificada como tal. Aparentemente as decisões eram tomadas coletivamente, mas havia ativistas mais engajados que acabavam assumindo certa coordenação, como pudemos registrar em nossa etnografia de observaçãoparticipante. Para a marcha de 2015, como cresceu o número de ativistas, aspectos pontuais da organização eram preparados de forma descentralizada, em comitês denominados "bondes".

Qualquer participante das reuniões preparatórias podia propor um bonde temático para desenvolver atividades em apoio à marcha. Para manter sua autonomia, difundir a mensagem e obter fundos, próximo à data da marcha eram organizadas palestras - Encontro Estadual Antiproibicionista - , venda de artigos para angariar fundos e exibições de filmes (THCine) seguidas de debates, que ocorriam em alguma localidade do campus da Universidade Federal do Espírito Santo. Os trabalhos preparativos ocorriam de acordo com a disponibilidade e habilidade de cada um, o que contribuiu à expressividade do evento.

Outro exemplo muito emblemático de resistência no repertório de ação e organização, com pautas dissidentes é o do Movimento Passe Livre (MPL). Variando de cidade a cidade do país em suas formas diversas de se reunir, mas presando pelos princípios do apartidarismo, da horizontalidade, da autonomia e da constituição de frente de luta que faz pressão por um 
objetivo específico (a redução da tarifa de transporte público), voltado a um horizonte exequível (a tarifa zero). Deriva dessas lutas uma ampla discussão acerca dos modos de vida nas cidades e a mercantilização de direitos sociais (em especial os transportes), apontando para uma crítica mais geral ao capitalismo e às formas de ação política contemporâneas.

Entre os grupos destacados aqui no âmbito da resistência e da dissidência, é importante considerar que suas atuações e modelos organizativos não são idênticos nem nas formas nem nos significados. Nossa tentativa de aproximar as experiências empíricas de conceitos teóricos, visando extrair dos primeiros significados inteligíveis para a sociologia política, não pode simplisticamente ser reduzida à uma equivalência dos objetos significantes. Os atos do MPL, por exemplo, por sua implacável exigência da tarifa zero, descortinou a lógica lucrativa por trás das políticas tarifárias no transporte público. Seus atos desafiadores da ordem pública evidenciaram, pelo espetáculo da destruição de vidraças por black blocs, a descontrolada violência policial em todo o país.

Sem dúvida nenhuma a resistência articulada à dissidência, ou seja, a pautas de incumbência do Estado, produziu uma chacoalhada nas instituições políticas, evidenciando suas falhas insuperáveis na capacidade de diálogo com a sociedade em espaços de interação que não foram articulados de cima para baixo. O MPL, que iniciou as mobilizações de 2013, é composto por militantes que também participaram dos movimentos que aqui encontramos como práticas de resistência na organização ou na ação. Ou seja, suas particularidades e sua potência não ocorrem de forma isolada, mas como consequência da cultura militante de resistência também verificada nos demais grupos descritos nesta sessão. Em termos de impacto, o MPL obteve melhores resultados em visibilidade, não só em São Paulo, mas também na Grande Vitória e em diversas capitais do país.

\section{A tática black bloc como marco do repertório de resistência}

A ação da tática black bloc, de resistência a governamentalidades pode ser entendida como de constituição radical no campo de luta e exercício de práticas de "cultura libertária". Emblemática para a resistência, a tática busca expressar o exercício da liberdade contra relações de poder inibidoras da autonomia:

(...) as práticas anarquistas devem ser compreendidas não apenas como projeto de emancipação humana, mas, antes, como lutas que, ao buscarem a sociedade livre da opressão do Estado (seja pelo revolucionarismo bakunista, ou pelo pacifismo proudhoniano) e do exercício da autoridade centralizada, fomentam práticas de 
liberdade que corroem o exercício da autoridade e do Estado (Augusto, 2017:146147).

A partir deste entendimento pode-se distinguir que a atuação de ativistas nos blocos de ação direta black blocs é ao mesmo tempo uma ação que articula o âmbito individual e coletivo na luta pela ampliação de liberdades. Enquanto luta libertária, a ação direta desafia a autoridade policial e despreza os mandamentos morais impostos pela ordem jurídica. Não se formaliza em organização e nem se constitui através de uma coordenação central. Quebrar as regras morais e jurídicas, em uma ação coletiva, eleva o nível do confronto político, expondo uma nova e incontrolável arena de política anti-institucional. Se descortina assim que os espaços e os significados da política não são tão consensuais quanto o contrato social permitiria supor.

Dupuis-Déri (2014) identificou uma ampla variedade de perfis de participantes, de enfermeiras a advogados, de professores a assistentes sociais. Nesses blocos de ação direta em protestos, ativistas com rosto e corpo cobertos de preto praticam coletivamente uma tática de de resistência, antagônica a saberes constituídos que determinam como se deve realizar atividades políticas. As ações de praticantes da tática são performativas de uma violência simbólica, complementar a outros ativismos que têm se mostrado insuficientes para expressar a dimensão da discordância política e social.

\section{Novas configurações das ações coletivas}

Movimentos sociais e grupos organizados buscam, no âmbito da ação coletiva, modificar, transformar, visibilizar ou conservar condições sociais críticas, ou problemas públicos, que entendem não estar recebendo a devida atenção de governantes ou de outros setores da sociedade. Tradicionalmente, esses movimentos têm se organizado e atuado de maneira que reproduz em vários aspectos o empreendedorismo neoliberal, sempre pautado em termos de ganhos (Foucault, 2008). Organizações hierárquicas, papéis fundamentais de lideranças, objetividade relacional, estratégias racionais, elos e alianças com outras organizações e partidos políticos, são aspectos que assemelham movimentos sociais a empresas privadas, ou que os confundem como apêndices do Estado.

Em uma das primeiras tradições de estudo de movimentos sociais, McCarthy e Zald (1987), na década de 1960 nos Estados Unidos, buscando compreender os traços principais dos movimentos de classe média, estabeleceram as linhas gerais da Teoria de Mobilização de Recursos. Com abordagem baseada na sociologia organizacional e nas teorias de ação 
racional, descreveram o que entendiam como os principais aspectos das organizações sociais. Atualmente, tais formatos de movimentos são vistos em organizações não governamentais, associações e grupos organizados tradicionais. Um crescente número de ativistas tem verificado, entretanto, que tal modelo organizativo, ainda que demonstre alguma eficiência em seus resultados, permanece subordinado a posicionamentos que não ameaçam os interesses dos governantes e dos principais tomadores de decisões. Ou seja, possuem limitações importantes nas possibilidades de produzir transformação social. Com a governamentalização do Estado (Foucault, 2006), que implica governar o Estado a partir de saberes específicos que também serão utilizados para os indivíduos governarem suas condutas, se reproduz nos sujeitos e grupos sociais padrões organizativos racionalburocráticos. Esses padrões possibilitam diálogos com representantes das instituições estatais e resultam em políticas limitadas pelos interesses de poder que sustentam o Estado e seus governos.

A partir da percepção sobre a maior possibilidade de cooptação de lideranças, o baixo potencial conflitivo e a baixa capacidade de promover transformações estruturais mais profundas e movimentos mais afins à resistência tem se distanciado de tais formatos organizativos. A capacidade das instituições liberais de capturar líderes, movimentos e lutas tem demonstrado que a proximidade com essas instituições a longo prazo é danosa para as lutas que buscam transformações profundas nas estruturas sociais, políticas e econômicas. As reformas que as instituições liberal-democráticas são capazes de implementar não alteram as origens dos problemas tornados públicos, levando por vezes os ativistas à radicalização do confronto e ao distanciamento a essas instituições (Cf. McAdam; Tarrow; Tilly, 2001; Tarrow, 2009).

$\mathrm{Na}$ sociedade de controle, em que as condutas individuais e coletivas são vigiadas e controladas a todo momento e em todos os espaços (Deleuze, 2001), a principal via de escape que se abre é a de resistir ao sistema no cotidiano, tanto em suas micropolíticas moleculares que fluem entre os indivíduos, moldando e vigiando condutas, quanto nas macropolíticas das instituições (Deleuze; Guattari, 1996). Neste cenário, multiplicam-se as formas de resistência e os movimentos sociais atingem uma feição menos formalizada, menos programada para ações futuras, mais direcionadas para o encontro de afinidades. Geram-se grupos de afinidade, em que a militância é exercida na vida cotidiana e nos encontros com os afins.

As ações coletivas, de resistência, são ações imediatas. Propõe-se, assim, uma vida marcada por singularidades não governamentalizadas pela lógica imperante da racionalidade do mercado. Plataformas de ação coletiva, redes de mobilização, táticas de protesto e grupos 
de afinidade têm sido crescentemente identificados como os principais formatos dos movimentos sociais atualmente, juntamente com a inserção de elementos típicos do anarquismo, que tem marcado essas novas tendências que nos levam a pensar numa ampliação da cultura libertária (Augusto, 2017; Day, 2005; Graeber, 2015).

Vale ainda destacar que os governos de tradição liberal democrática, pautados pelo diálogo com a sociedade através de mecanismos predominantemente representativos, nas últimas décadas têm buscado diálogo também através de mecanismos de participação direta, o que corresponderia, como já destacado, a elementos característicos da sociedade de controle (Deleuze, 2001). No Brasil, esse modelo de gestão se destacou com a administração petista da prefeitura de Porto Alegre, a partir de 1988, e se expandiu para diversos municípios (Genro; Souza, 1997). Entretanto, as instituições participativas e outras modalidades formalizadas de interação de grupos sociais com o Estado, frequentemente são utilizadas para legitimar decisões previamente tomadas e fortalecer o capital político de partidos, suas lideranças e grupos associados (Navarro, 1999).

\section{Considerações finais}

Esta pesquisa não pretendia estabelecer uma fotografia estática e absoluta das formas organizativas e de ação política militante. O objetivo foi partir da interação com essas práticas para lançar mão de observações e avaliações que atribuam sentido às experiências, na medida em que as diferenciamos mutuamente. Os contrastes que estabelecemos não tiveram a finalidade de realizar juízos de valor sobre as melhores ou piores práticas, ou esperar que o que acontece em um lado acontecerá em outro, ou, ainda, apontar as semelhanças entre as práticas. Pelo contrário, nos inspiramos principalmente a observar as diferenças, as singularidades, as criatividades e inovações de cada coletivo ou movimento com suas formas de organização e seus repertórios de ação, avaliando suas rupturas e continuidades em termos políticos. São exatamente essas diferenças que os movimentos têm de mais enriquecedor.

Ao analisar a diversidade de movimentos e suas formas organizativas, o que encontramos foi uma criatividade social que impressiona na diversidade de atuações, mas que se coincide em determinadas formas de organização que, por já estarem bem estabelecidas e adequadas às normas, consideramos de captura. Destaca-se também a coerência com que grupos próximos à resistência se inspiram em referências anarquistas na forma de organização ou nos repertórios de ação que desafiam a ordem. Assim, grupos mais combativos, de lutas radicalizadas, tendem a se organizar de forma mais informal e 
horizontalizada, prezando pela autonomia e a autogestão, enquanto os grupos mais estabelecidos tendem a ser melhores negociadores com partidos e representantes dos governos, com demandas precisas e afinidade com agendas políticas governamentais.

Julgamos importante divisar algumas nuances na captura já que sem o rompimento radical com a ordem estabelecida pode-se atuar na incidência, com a busca de diálogo e interlocução com o governo, ou na dissidência, com o bloqueio e o confronto reivindicativo. Os repertórios, entretanto, são diversos e a categorização de que aqui nos aproximamos tem a função de tornar essa diversidade inteligível, facilitando a diferenciação na análise sociológica.

Os traços descritivos que podemos identificar como novíssimos movimentos, ou seja, o que há de mais inovador no ativismo que pesquisamos, são atualizações e reinterpretações de posturas anarquistas, como já havia antecipado Day (2005). As instituições estatais e a esquerda tradicional, após anos de acomodação no neoliberalismo global, ficaram desacreditadas como capazes de promover transformações sociais importantes. Para os movimentos que buscam atuar fora das instituições, essa esquerda tradicional já não serve mais como interlocutora ou inspiradora de movimentos e lutas sociais. Com a hiperconectividade das novas tecnologias e os algoritmos das redes sociais se estabelecendo como catalizadores de bolhas ideológicas e da disseminação de narrativas não acomodadas no establishment, abre-se espaço para o pensamento radical e a crítica às instituições políticas representativas.

Apesar de não ter sido o foco deste trabalho, é importante considerar que nesse contexto emergem movimentos com princípios coletivistas e de solidariedade aos oprimidos, lutando contra todas as formas de opressões, mas, em contrapartida, também emergem movimentos neofascistas, que pregam a eliminação de oponentes e de grupos de indivíduos. Sendo assim, a polarização tem marcado muito o ativismo hodierno, repercutindo de forma similar nas instituições políticas representativas de diversos países. Fato que precisará ser mais explorado em futuros trabalhos que estejam interessados em considerar as últimas novidades nessa seara, assim como na avaliação sobre até que ponto as noções de captura e de resistência são úteis para ponderar as continuidades e rupturas políticas desses movimentos neofascistas.

Por último, neste trabalho adotamos a abordagem cartográfica que foca nos fluxos, que, entre outros aspectos, pressupõe que movimentos sociais não são estáticos a configurações organizativas e a repertórios de ação que adotam em um determinado momento. A cada ciclo de mudanças, portanto, abre-se necessidade de atenção a seus novos 
direcionamentos. Como a pesquisa de campo foi realizada no contexto do ciclo de protestos de junho de 2013, que entendemos que se estendeu até os atos contra a Copa do Mundo de 2014, seria salutar analisar como os grupos aqui descritos se renovaram no atual contexto de avanço do neofascismo e de mudanças na política institucional brasileira.

\section{Referências}

ABERS, R. e VON BÜLOW, M. (2011), "Movimentos Sociais na Teoria e na Prática: como estudar o ativismo através da fronteira entre Estado e sociedade?". Sociologias, Porto Alegre, v. 13, n. 28, pp. 52-84 [Consult. 30-11-2020]. Disponível em https://www.scielo.br/pdf/soc/v13n28/04.pdf

AUGUSTO, Acácio (2017), "Lutas anarquistas hoje: entre a utopia e as heterotopias". Cosmos e Contextos, n. 29, pp. 1-17 [Consult. 27-07-2020].

Disponível em https://cosmosecontexto.org.br/category/edicoes/cosmos-e-contexto-n-29-set-2017

AUGUSTO, Acácio.; ROSA, Pablo. O.; RESENDE, Paulo E. R. (2016), "Capturas e resistências nas democracias liberais: uma mirada sobre a participação dos jovens nos novíssimos movimentos sociais". Estudos de Sociologia, v. 21, n. 40, pp. 21-37 [Consult. 02-12-2020]. Disponível em https://periodicos.fclar.unesp.br/estudos/article/view/7581/5792

BRANCO, Guilherme Castelo (2001), "As Resistências ao Poder em Michel Foucault". Trans/Form/Ação, São Paulo, v. 24, pp. 237-248 [Consult. 02-12-2020]. Disponível em https://revistas.marilia.unesp.br/index.php/transformacao/article/view/837/731

CARLOS, Euzeneia. (2011), "Movimentos Sociais: revisitando a participação e a institucionalização". Lua Nova, São Paulo, v. 84, pp. 315-348 [Consult. 02-12-2020]. Disponível em https://www.scielo.br/pdf/ln/n84/a11n84.pdf

CASTELLS, Manuel (2013), Redes de Indignação e Esperança: movimentos sociais na era da internet. Rio de Janeiro, Zahar.

DA SILVEIRA, Sérgio Amadeu (2018), "A noção de modulação e os sistemas algorítmicos". In: JOYCE, S; RODOLGO, A; DA SILVEIRA, S.A. (Org.). A Sociedade de Controle: manipulação e modulação nas redes digitais. São Paulo, Hedra.

DAY, Richard J. F. (2004), "From hegemony to affinity: the political logic of the newest social movements". Cultural Studies, v. 18, n. 5, pp. 716-748 [Consult. 02-12-2020]. Disponível em https://www.tandfonline.com/doi/abs/10.1080/0950238042000260360 Press.

. (2005), Gramsci is Dead: anarchist currents in the newest social movements. Londres, Pluto

DELEUZE, Gilles (2001), "Post-Scriptum: sobre as sociedades de controle". In: G. Deleuze. Conversações. São Paulo, Editora 34.

DELEUZE, Gilles. e GUATTARI, Felix. (1996), Mil platôs: capitalismo c esquizofrenia, vol. 3. Trad. Aurélio Guerra Neto et alii. Rio de Janeiro, Ed. 34.

DELLA PORTA, Donatella e TARROW, Sidney (2005), Transnational Protest and Global Activism. Lanham, Rowman \& Littlefield Publishers, inc. 
DUPUIS-DÉRI, Francis. (2014), Black Blocs. Trad. G. Miranda. São Paulo, Veneta.

FOUCAULT, Michel (2006), Microfísica do Poder. Rio de Janeiro, Graal.

(2008), Nascimento da Biopolítica: Curso dado no Collège de France (1978-1979). Trad. Eduardo Brandão. São Paulo, Martins Fontes.

(2009), "O Sujeito e o Poder", In: H. Dreyfus e P. Rabinow (Orgs.), Michel Foucault: uma trajetória filosófica. Para além do estruturalismo e da hermenêutica. Trad. Vera Portocarrero e Gilda G. Carneiro. Rio de Janeiro, Forense Universitária.

GENRO, Tarso e SOUZA, Ubiratan de (1997), Orçamento Participativo: a experiência de Porto Alegre. São Paulo, Editora Perseu Abramo.

GOHN, Maria da Glória (2013), Sociologia dos Movimentos Sociais. São Paulo, Cortez.

. (2017), Manifestações e protestos no Brasil: correntes e contracorrentes na atualidade. São Paulo, Cortez.

GRAEBER, David (2015), Um Projeto de Democracia: uma história, uma crise, um movimento. São Paulo, Paz e Terra.

LACLAU, Ernesto.; MOUFFE, Chantal (2015), Hegemonia e Estratégia Socialista: por uma política democrática radical. São Paulo, Intermeios.

LAVALLE, Adrian G.; VON BÜLOW, Marisa. (2014), "Sociedade Civil e Institucionalização da Intermediação: brokers diferentes, dilemas semelhantes". Política \& Sociedade, Florianópolis, v. 13, n. 28, pp. 125-165 [Consult. 02-12-2020]. Disponível em https://periodicos.ufsc.br/index.php/politica/article/view/2175-7984.2014v13n28p125/28901

MCADAM, Doug (1982), Political Process and the Development of Black Insurgency 1930-1970. Chicago, University of Chicago Press.

MCADAM, Doug. (1994), “Cultura y Movimientos Sociales”, In: E. Laraña e J. Gusfield (Orgs.), Los Nuevos Movimientos Sociales: de la ideología a la identidad. Madri, CIS.

McADAM, Doug; TARROW, Sidney; TILLY, Charles (2001), Dynamics of Contention. Cambridge, Cambridge University Press.

McADAM, Doug; MCCARTHY, John D.; ZALD, Mayer (1999), "Oportunidades, estructuras de movilización y procesos enmarcadores: hacia uma perspectiva sintética y comparada de los movimientos sociales", in D. Mcadam; J. Mccarthy; M. Zald (Orgs.), Movimientos Sociales: perspectivas comparadas. Trad. Sandra Chaparro. Madrid, Istmo.

McCARTHY, Jhon D.; ZALD, Mayer (1987), "Resource mobilization and social movements: a partial theory", in J. McCarthy; M. Zald (Orgs.), Social movements in a organizational society. New Jersey, Transaction Publishers, pp. 247-272.

MELUCCI, Alberto (1994), “Qué hay de nuevo en los nuevos movimientos sociales?” In: E. Laraña e J. Gusfield (Orgs.), Los Nuevos Movimientos Sociales: de la ideología a la identidad. Madri, CIS.

NAVARRO, Clemente. J. (1999), El Sesgo Participativo. Madrid, CSIC.

NEGRI, Antonio; HARDT, Michael. (2014), Declaração - isto não é um manifesto. São Paulo, N-1 edições.

NEWMAN, Saul (2005), "Guerra ao Estado: O Anarquismo de Stirner e Deleuze”. Verve, São Paulo, v. 8, pp. 13-41. Disponível em https://revistas.pucsp.br/index.php/verve/article/view/5042 [Consult. 
02-12-2020].

PASSETTI, Edson (2003), Anarquismos e Sociedade de Controle. São Paulo, Cortez.

(2007), "Poder e Anarquia: apontamentos libertários sobre o atual conservadorismo moderado". Verve, São Paulo, v. 12, pp. 11-43 [Consult. 02-12-2020] .Disponível em https://revistas.pucsp.br/index.php/verve/article/view/5448/3895

PEREZ, Olivia C.; SOUZA, Bruno M. (2017), "Velhos, novos ou novíssimos movimentos sociais? As pautas e práticas dos coletivos", in 41 ancontro Anual da ANPOCS. Caxambu, ANPOCS [Consult. 02-12-2020]. Disponível http://anpocs.com/index.php/encontros/papers/41-encontroanual-da-anpocs/gt-30/gt11-15/10696-velhos-novos-ou-novissimos-movimentos-sociais-as-pautase-praticas-dos-coletivos/file

RESENDE, Paulo E. R.; ROSA, Pablo O. (2017), "Ativismo Identitário e o Capital Subalterno". Gavagai, v. 4, n. 1, pp. 245-265 [Consult. 02-12-2020]. Disponível em https://periodicos.uffs.edu.br/index.php/GAVAGAI/article/view/9002/5605

ROLNIK, Suely. (1989), Cartografia Sentimental: transformações contemporâneas do desejo. São Paulo, Estação Liberdade.

ROSA, Pablo O.; REZENDE, Rafael A.; MARTINS, Victória M. V. (2018), "As consequências do etnocentrismo de Olavo de Carvalho na produção discursiva das novíssimas direitas conservadoras brasileiras". Revista NEP - Núcleo de Estudos Paranaenses da UFPR, v. 4, n. 2 pp. 164-203 [Consult. 02-12-2020]. Disponível em https://revistas.ufpr.br/nep/article/view/63832/37139

SCHOPKE, Regina. (2012), Por uma Filosofia da Diferença: Gilles Deleuze, o pensador nômade. Rio de Janeiro, Contraponto.

SUBIRATS, Joan, (2005), "Democracia, participación y transformacion social". Polis Revista Latinoamericana, Santiago, v. 12 [Consult. 02-12-2020]. Disponível em https://journals.openedition.org/polis/5599

TARROW, Sidney (2005), The New Transnational Activism. Cambridge, Cambridge University Press.

TILLY, Charles (1978), From Mobilization to Revolution. New York: Random House.

TÓTORA, Silvana (2006), "Democracia e sociedade de controle". Verve, n. 10, pp. 237-261 [Consult. 02-12-2020]. Disponível em https://revistas.pucsp.br/index.php/verve/article/view/5441/3888 


\begin{abstract}
The amplification of the range of organizational, relational, and action repertoire have been taking place in the current activism, which raises the necessity to observe and analyze such diversity with its respective political meanings. With this purpose and based on the notions of capture, dissidence, incidence, and resistance, we discuss the intensities with which different groups and movements in the Great Vitoria area reproduce or break down norms and patterns of organization, relation, and action. With several data collection technics and with analysis based on post-structuralist political propositions, we discuss groups' innovations and singularities considering their potential to provoke social transformation. The major innovations and potential were found among those that could be called the newest social movements or collectives, which are the ones that most concentrate resistance attributes.
\end{abstract}

Keywords: Social movements; resistance; activism; post-structuralism.

\title{
Resumen
}

En el activismo moderno se ve una amplificación de la gama de repertorios organizativos, relacionales y de acción, haciéndose necesario observar y analizar esta diversidad con sus respectivos sentidos políticos. Para tal, discutimos las intensidades con las que distintos colectivos y movimientos del área de Grande Vitória, en el momento de la investigación en el curso de 2013, reproducían o rompían con padrones organizativos, relacionales y de los repertorios de acción, con base a las nociones de captura, disidencia, incidencia y resistencia. Con distintas técnicas de captación de datos y análisis basada en proposiciones políticas postestructuralistas, discutimos las innovaciones y las singularidades de los grupos considerando sus potenciales de provocar transformaciones sociales. Las innovaciones más contundentes han sido halladas en aquellos que se puede denominar nuevísimos movimientos sociales o colectivos, que son los que más se acercan a las formulaciones de resistencia.

Palabras clave: Movimientos sociales; resistências; activismo; postestructuralismo. 